\title{
Emisi Radiasi Speaker Aktif pada Frekuensi 30 Mhz - 1 Ghz dan $1-6 \mathrm{Ghz}$
}

\author{
Active Speaker Radiated Emission at Frequencies $30 \mathrm{MHz}-1 \mathrm{GHz}$ and 1 - 6 \\ $\mathrm{GHz}$
}

\author{
Agung Yanuar Wirapraja \\ Balai Riset dan Standardisasi Industri Surabaya \\ Kementerian Perindustrian \\ Surabaya, Indonesia \\ agungyanuar1945@gmail.com
}

\author{
Mohamad Marhaendra Ali \\ Balai Riset dan Standardisasi Industri Surabaya \\ Kementerian Perindustrian \\ Surabaya, Indonesia \\ ali_industri@yahoo.com
}

\begin{abstract}
Abstrak- Speaker merupakan piranti atau komponen yang kedudukannya hampir tidak bisa dipisahkan lagi dengan perangkat elektronika lainnya. Speaker aktif banyak digunakan ditempat tinggal, rumah ibadah, perkantoran hingga pertokoan. Saat ini speaker aktif dilengkapi oleh beberapa fitur komunikasi nirkabel untuk mempermudah proses pengiriman suara yang akan dihasilkan. Kemajuan teknologi komunikasi nirkabel juga dapat menghasilkan radiasi elektromagnetik yang dapat memberikan gangguan perangkat elektronik lain yang ada disekitarnya. Penelitian ini secara khusus menganalisa emisi radiasi elektromagnetik pada speaker aktif. Penelitian ini menggunakan dua kelompok speaker aktif yaitu speaker aktif dengan kabel suplai listrik dan speaker aktif menggunakan baterai. Tujuan yang ingin dicapai pada penelitian ini adalah mengetahui pengaruh penggunaan kabel suplai listrik dan baterai terhadap nilai emisi radiasi speaker aktif. Metoda pengujian mengacu pada CISPR 32 yaitu emisi radiasi pada frekuensi $30 \mathrm{MHz}-1$ GHz dan 1 - 6 GHz. Speaker aktif dengan menggunakan baterai memiliki nilai emisi radiasi elektromagnetik yang lebih rendah jika dibandingkan speaker aktif dengan kabel suplai listrik langsung. Semua speaker aktif dengan baterai lulus persyaratan uji CISPR 32 emisi radiasi elektromagnetik pada frekuensi $30 \mathrm{MHz}-$ 1 GHz.
\end{abstract}

Kata Kunci: speaker aktif, radiasi elektromagnetik, baterai, CISPR 32

Abstract - Speaker is a device or component whose its position can hardly be separated with other electronic devices. Many active speakers are used in residence, place of worship, offices, and shops. Nowadays, active speakers are equipped with several wireless communication features to simplify the process of sound transmission that will be produced. Advances in wireless communication technology can also produce electromagnetic radiation that can cause interference with other electronic devices around them. This research specifically analyzes the emission of electromagnetic radiation on active speakers. This study uses two groups of active speakers, namely active speakers with power supply cables and active speakers using batteries. The objective of this study is to determine the effect of the use of power supply cables and batteries on the value of active speaker radiation emission. The test method refers to CISPR 32 with the emission of radiation at a frequency of $30 \mathrm{MHz}-1 \mathrm{GHz}$ with a measurement distance of 10 meters. Active speakers using batteries have lower electromagnetic radiation emission values than active speakers with direct power supply cables. All active speakers with batteries pass the CISPR 32 test requirements for electromagnetic radiation emission at a frequency of $30 \mathrm{MHz}-1 \mathrm{GHz}$.

Keyword : active speaker, electromagnetic radiation, battery, CISPR 32

\section{PENDAHULUAN}

Pengeras suara atau speaker adalah transduser yang mengubah sinyal elektrik ke frekuensi audio atau suara dengan cara menggetarkan komponen yang berbentuk membran untuk menggetarkan udara disekitarnya sehingga terjadi gelombang suara. Speaker merupakan piranti dengan kedudukannya hampir tidak bisa dipisahkan lagi dengan komputer atau perangkat elektronika lainnya. Karena itu. Produk-produk ITE (Information Telecomunication Equipment) dan multimedia memiliki komponen speaker didalamnya, speaker yang digunakan adalah tipe speaker pasif. Speaker aktif yang banyak digunakan oleh masyarakat pada umumnya untuk dipasang atau digunakan ditempat tinggal, rumah ibadah, perkantoran hingga pertokoan. Saat ini speaker aktif dilengkapi oleh beberapa fitur komunikasi untuk mempermudah proses pengiriman suara yang akan dihasilkan. Fitur komunikasi yang banyak digunakan saat ini adalah bluetooth.

Bluetooth adalah suatu metode komunikasi radio jarak pendek untuk mengganti kabel penghubung antara produk ${ }^{1}$. Bluetooth ditemukan pada tahun 1994 oleh L. M. Ericsson, Swedia. Perkembangan standar industri bluetooth dimulai pada akhir musim dingin 1998 ketika Ericsson, IBM, Intel, Nokia, dan Toshiba terbentuk Kelompok Industri Khusus Bluetooth (SIG) untuk mengembangkan dan mempromosikan 
komunikasi nirkabel yang beroperasi di $2.4 \mathrm{GHz}^{2}$. Bluetooth menggabungkan teknologi microchip dan frekuensi radio untuk menciptakan sistem yang aman yang dapat digunakan untuk identifikasi, pemantauan dan pemeliharaan inventaris objek. Sistem komunikasi bluetooth menggunakan chip kecil yang disebut "Tag", Tag itu sendiri berisi dan kemudian mengirimkan sebagian informasi yang dapat diidentifikasi ke bluetooth $^{3}$. Perangkat pintar diaktifkan. Teknologi Bluetooth sekarang dibagi menjadi 2 (dua) system, yaitu Low Energy (LE) dan Tingkat Dasar (BR $)^{4}$. Bluetooth Low Energy (BLE) adalah teknologi nirkabel baru berdaya rendah yang dikembangkan untuk komunikasi pendek antara produk, yang diharapkan dapat digunakan atau diaplikasikan oleh bermacam-macam produk ${ }^{5}$. Penggunaan teknologi nirkabel atau bluetooth tidak hanya memberikan dampak positif berupa mobilitas peralatan atau perangakat, bluetooth juga memberikan dampak negative yaitu seperti keandalan yang lebih rendah karena adanya gangguan, konsumsi daya yang lebih tinggi, keamanan data pada perangkat, keamanan pengguna karena pemaparan radio frekuensi, dan kecepatan data yang lebih rendah ${ }^{6}$. Perubahan atau kemajuan teknologi komunikasi nirkabel juga dapat menghasilkan radiasi elektromagnetik yang dapat memberikan gangguan perangkat elektronik lain yang ada disekitarnya ${ }^{7}$. Tidak hanya berdampak bagi perangkat elektronik, radiasi elektromagnetik juga dapat memberikan dampak bagi makhluk hidup dan dapat menimbulkan pencemaran elektromagnetik ${ }^{8,9}$.

EMC (Electromagnetic Compability) adalah kemampuan perangkat dalam melindungi diri dari lingkungan elektromagnetik serta kemampuan perangkat itu sendiri agar tidak menghasilkan emisi elektromagnetik ${ }^{10}$. Gangguan elektromagnetik atau yang sering disebut EMI (Electromagnetic Inference) merupakan emisi yang diakibatkan oleh sumbersumber noise melalui radiasi maupun konduksi elektromagnetik $^{11}$. Faktor yang mempengaruhi EMI dapat diklasifikasikan menjadi sifat dari perangkat elektronik yang memancarkan noise, jarak antara perangkat elektronika, dan kerentanan perangkat yang terkena elektromagnetik ${ }^{12}$. Radiated Emission (Emisi radiasi) adalah energi elektromagnetik yang dipancarkan oleh suatu perangakat elektronika dalam bentuk gelombang dan tidak memiliki massa ${ }^{13}$. Dalam mengurangi dampak dari emisi radiasi elektromagnetik yag dihasilkan oleh peralatan elektronik maka diperlukan regulasi batasan maksimum gelombang elektromagnetik yang dipancarkan atau dihasilkan oleh peralatan elektronik. CISPR (Comité International Spécial des Perturbations Radioélectriques) atau dalam Bahasa Inggris disebut International Special Committee on Radio Interference adalah badan standar EMC yang biasa dijadikan acuan oleh dunia internasional ${ }^{14}$. Penelitian ini bertujuan untuk mengetahui karakteristik emisi radiasi (Radiated Emission) speaker aktif pada frekuensi $30 \mathrm{MHz}-1 \mathrm{GHz}$ dan frekuensi $1 \mathrm{GHz}-6 \mathrm{GHz}^{15}$. Parameter yang digunakan dalam pengukuran emisi radiasi (Radiated Emission) adalah nilai Quasipeak dan margin Quasipeak, nilai maks. peak dan margin maks. peak antara hasil pengukuran dengan limit yang terdapat pada CISPR 32. Semakin tinggi nilai margin Quasipeak dan maksimum peak maka semakin rendah emisi radiasi yang dihasilkan.

\section{BAHAN DAN METODE}

Metode pengujian mengacu pada CISPR 32 Edition 2.0 : 2015-03 : Electromagnetic compatibility of multimedia equipment - Emission requirements. Pengujian yang dilakukan adalah emisi radiasi 10 meter,sesuai pada CISPR $32^{16}$. Pengukuran emisi radiasi dilakukan pada frekuensi $30 \mathrm{MHz}-1 \mathrm{GHz}$ pada jarak 10 meter dan $1-6 \mathrm{GHz}$ pada jarak 3 meter. Speaker aktif akan dianggap gagal apabila ada nilai quasipeak yang melebihi nilai limitnya. Nilai limit quasipeak dan limit maksimum peak (Max.peak) sesuai dengan CISPR 32 untuk produk multimedia, seperti pada Tabel I dan Tabel II.

Tabel 1. Batas emisi radiasi pada frekuensi $30 \mathrm{MHz}-1 \mathrm{GH}$
\begin{tabular}{|c|c|}
\hline Frequency range & $\begin{array}{c}\text { Limits } \\
\mathrm{dB}(\mu \mathrm{V})\end{array}$ \\
\cline { 2 - 3 } & Quasipeak \\
\hline $30 \mathrm{MHz}-230 \mathrm{MHz}$ & 30 \\
\hline $230 \mathrm{MHz}-1 \mathrm{GHz}$ & 37 \\
\hline
\end{tabular}

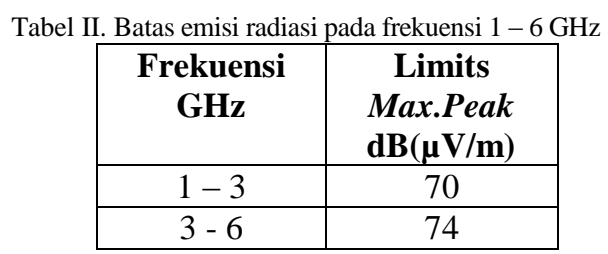

Penelitian ini menggunakan speaker aktif dengan suplai langsung dan speaker aktif menggunakan baterai. Baterai adalah sebuah sel listrik dimana didalamnya berlangsung proses elektrokimia yang reversible (dapat berkebalikan) dengan efisiensi yang tinggi. Reaksi elektrokimia reversibel adalah berlangsungnya proses pengubahan kimia menjadi tenaga listrik (proses pengosongan) dan sebaliknya dari tenaga listrik menjadi tenaga kimia (proses pengisian) dengan cara proses regenerasi dari elektroda - elektroda dengan melewatkan arus listrik dalam arah polaritas yang berlawanan didalam sel baterai ${ }^{17}$. Baterai menghasilkan listrik melalui proses kimia. Jumlah sampel yang digunakan adalah 12 buah speaker aktif. Speaker aktif dibagi menjadi 2 (dua) kelompok, berdasarkan sumber daya yang digunakan yaitu, kabel suplai langsung ke jala-jala PLN dan menggunakan baterai. Spesifikasi sampel yang digunakan dapat dilihat pada Tabel II.

Sesuai standar yang dipakai, Pengujian dilakukan pada ruangan semi anechoic chamber. Benda uji (Equipment Under Test / EUT) diletakkan pada meja di round area (berdiameter 3 meter). Benda uji dihubungkan dengan perangkat pendukung berupa computer tablet dengan sambungan bluetooth. Perangkat pendukung (AE) memberikan input atau masukan kepada benda uji yaitu beban $1 \mathrm{KHz}$ dan benda uji di setting pada suara maksimal. Meja yang 
digunakan bersifat non konduktif, dengan ukuran 1,5 meter x 1 meter x 1,5 meter. Pada saat pengukuran, round area berputar dari $0^{\circ}$ hingga $360^{\circ}$. Antena ditempatkan pada antena mast yang berjarak 10 meter dan 3 meter dari EUT. Pada saat pengujian emisi radiasi $1-6 \mathrm{GHz}$, kondisi ruangan diubah dari semi anechoic chamber menjadi full anechoic chamber dengan penambahan absorber pada lantai, seperti pada gambar 1 dan gambar 2. Pengukuran dilakukan pada ketinggian antena bervariasi antara 1 sampai 4 meter (per 1 meter) dengan posisi antena vertikal dan horisontal. Proses perputaran round area dan pergeseran posisi antena dikontrol oleh perangkat Controller CO3000 yang disambung secara otomatis melalui software EMC32. Nilai emisi yang dihasilkan EUT ditangkap oleh antena yang tersambung ke EMI Test Receiver. Hasil pengujian dapat diamati melalui software EMC 32. Frekuensi range pengukuran adalah $30 \mathrm{MHz}$ hingga $1 \mathrm{GHz}$. Pengukuran dilakukan pada tegangan jala-jala PLN sebesar 220 Volt. Pada setiap pengujiannya akan diambil 5 titik quasipeak tertinggi untuk dianalisa.

Tabel III. Spesifikasi speaker aktif

\begin{tabular}{|c|c|c|c|c|}
\hline Kelompok & Sampel & $\begin{array}{c}\text { Daya } \\
\text { (Watt) }\end{array}$ & $\begin{array}{c}\text { Baterai } \\
(\mathrm{mAh})\end{array}$ & $\begin{array}{c}\text { Bluetooth } \\
\text { Version }\end{array}$ \\
\hline \multirow{9}{*}{$\begin{array}{c}\text { Kelompok } 1 \\
\text { (Baterai) }\end{array}$} & $\mathrm{SB}_{1}$ & 3 & 600 & 5,0 \\
\hline & $\mathrm{SB}_{2}$ & 3 & 1800 & 5,0 \\
\hline & $\mathrm{SB}_{3}$ & 5 & 1200 & 4,2 \\
\hline & $\mathrm{SB}_{4}$ & 5 & 1000 & $2,1+\mathrm{EDR}$ \\
\hline & $\mathrm{SB}_{5}$ & 5 & 1000 & $2,1+\mathrm{EDR}$ \\
\hline & $\mathrm{SB}_{6}$ & 10 & 3000 & 4,2 \\
\hline & $\mathrm{SB}_{7}$ & 30 & 1200 & 2,1 \\
\hline & $\mathrm{SB}_{8}$ & 5 & 2000 & 4,0 \\
\hline & $\mathrm{SB}_{9}$ & 5 & 1200 & 2,1 \\
\hline Kelompok & Sampel & $\begin{array}{c}\text { Daya } \\
\text { (Watt) }\end{array}$ & $\begin{array}{c}\text { Tegangan } \\
\text { (Volt) }\end{array}$ & $\begin{array}{c}\text { Bluetooth } \\
\text { Version }\end{array}$ \\
\hline \multirow{9}{*}{$\begin{array}{c}\text { Kelompok } 2 \\
\text { (non } \\
\text { Baterai) }\end{array}$} & $\mathrm{SN}_{1}$ & 75 & $100-240$ & 4,2 \\
\hline & $\mathrm{SN}_{2}$ & 16 & $\begin{array}{l}100-240 \\
(\mathrm{DC} 9 \mathrm{~V})\end{array}$ & 3,0 \\
\hline & $\mathrm{SN}_{3}$ & 105 & $220-240$ & 2,0 \\
\hline & $\mathrm{SN}_{4}$ & 25 & $220-240$ & 2,0 \\
\hline & $\mathrm{SN}_{5}$ & 100 & $220-240$ & 3,0 \\
\hline & $\mathrm{SN}_{6}$ & 130 & $100-240$ & 4,2 \\
\hline & $\mathrm{SN}_{7}$ & 15 & 220 & 2,0 \\
\hline & $\mathrm{SN}_{8}$ & 85 & 220 & 4,2 \\
\hline & $\mathrm{SN}_{9}$ & 38 & $100-240$ & $2,1+\mathrm{EDR}$ \\
\hline
\end{tabular}

Hasil pengukuran berupa margin yang merupakan selisih nilai antara batas limit yang terdapat pada CISPR 32 dengan nilai qusipeak hasil pengukuran. Seluruh penelitian dilakukan di Laboraturium EMC Baristand Industri Surabaya, dengan menggunakan alat ukur yang telah terkalibrasi dengan baik.

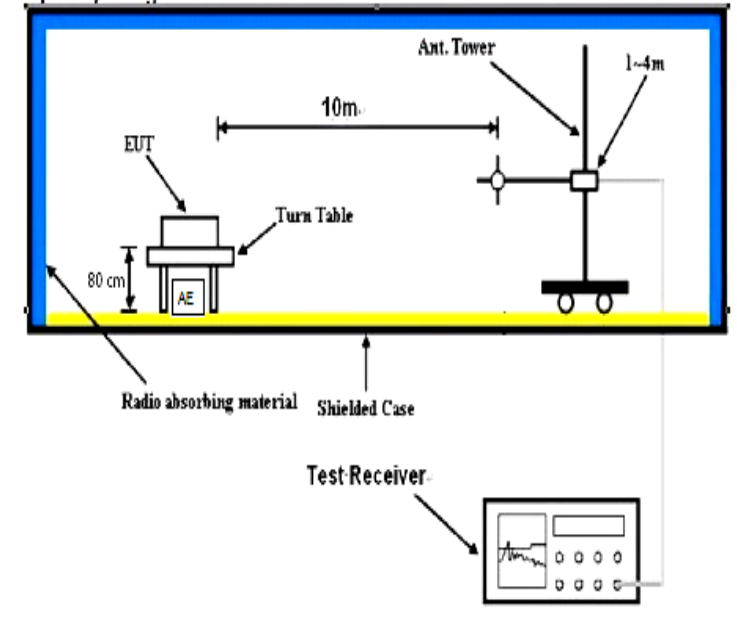

Gambar 1. Pengujian emisi radiasi pada frekuensi $30 \mathrm{MHz}-1$ $\mathrm{GHz}$

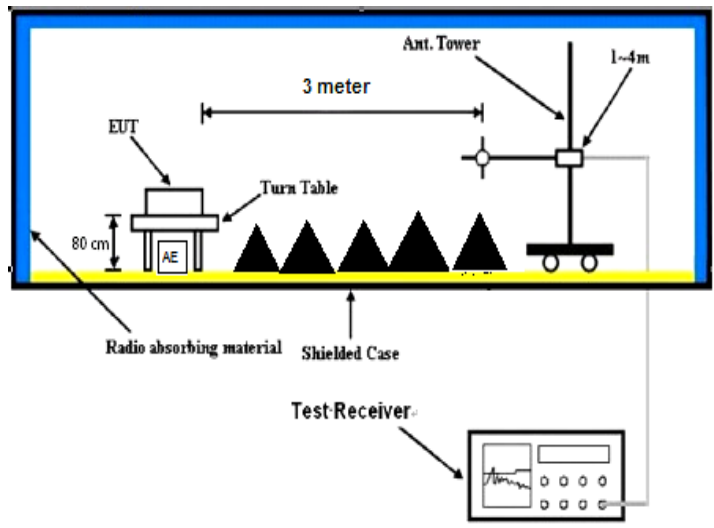

Gambar 1. Pengujian emisi radiasi pada frekuensi $1-6 \mathrm{GHz}$

\section{HASIL DAN PEMBAHASAN}

A. EMISI RADIASI FREKUENSI $30 \mathrm{MHz}-1 \mathrm{GHz}$

Hasil pengambilan data pengukuran emisi radiasi speaker aktif dilakukan dalam kondisi suhu ruang yang dikontrol. Ada dua (2) jenis speaker aktif yang digunakan yaitu, speaker aktif dengan sumber daya listrik berupa baterai dan speaker aktif dengans umber daya listrik PLN. Adapun variabel atau besaran yang diukur meliputi nilai quasipeak (Qp) dan margin quasipeak. Hasil pengukuran nilai quasipeak pada frekuensi $30 \mathrm{MHz}-1 \mathrm{GHz}$, speaker aktif dengan sumber daya baterai (SB) diperlihatkan pada Tabel IV, 5 dan 6. Sedangkan hasil pengukuran speaker aktif dengan kabel suplai langsung (SN) diperlihatkan pada Tabel VII, 8 dan 9.

Tabel IV. Hasil pengukuran emisi radiasi $30 \mathrm{MHz}-1 \mathrm{GHz}$ Speaker $\mathrm{SB}_{1}, \mathrm{SB}_{2}$ dan $\mathrm{SB}_{3}$

\begin{tabular}{|c|c|c|c|c|c|}
\hline \multicolumn{2}{|c|}{$\mathbf{S B}_{\mathbf{1}}$} & \multicolumn{2}{c|}{$\mathbf{S B}_{\mathbf{2}}$} & \multicolumn{2}{c|}{$\mathbf{S B}_{\mathbf{3}}$} \\
\hline $\boldsymbol{Q p}$ & Margin & $\boldsymbol{Q p}$ & Margin & $\boldsymbol{Q p}$ & Margin \\
\hline $\mathbf{( d B} \boldsymbol{\mu} \mathbf{V})$ & $\mathbf{( d B})$ & $(\mathbf{d B} \boldsymbol{\mu} \mathbf{V})$ & $(\mathbf{d B})$ & $(\mathbf{d B} \boldsymbol{\mu V})$ & $(\mathbf{d B})$ \\
\hline 19,56 & 10,44 & 19,79 & 10,21 & 21,90 & 8,10 \\
\hline 12,53 & 17,47 & 26,40 & 10,60 & 23,58 & 6,42 \\
\hline 10,27 & 19,73 & 26,44 & 10,56 & 23,93 & 6,07 \\
\hline 16,23 & 20,77 & 27,32 & 9,68 & 25,00 & 5,00 \\
\hline 18,28 & 18,72 & 26,84 & 10,16 & 24,80 & 5,20 \\
\hline
\end{tabular}


Tabel V. Hasil pengukuran emisi radiasi $30 \mathrm{MHz}-1 \mathrm{GHz}$ Speaker $\mathrm{SB}_{4}, \mathrm{SB}_{5}$ dan $\mathrm{SB}_{6}$

\begin{tabular}{|c|c|c|c|c|c|}
\hline \multicolumn{2}{|c|}{$\mathbf{S B}_{4}$} & \multicolumn{2}{|c|}{$\mathbf{S B}_{5}$} & \multicolumn{2}{|c|}{$\mathrm{SB}_{6}$} \\
\hline$Q p$ & Margin & $Q p$ & Margin & $Q p$ & Margin \\
\hline$(\mathrm{dB} \mu \mathrm{V})$ & (dB) & $(d B \mu V)$ & (dB) & $(d B \mu V)$ & (dB) \\
\hline 19,49 & 10,51 & 19,52 & 10,48 & 32,58 & 4,42 \\
\hline 15,63 & 21,37 & 11,85 & 18,15 & 33,30 & 3,70 \\
\hline 17,00 & 20,00 & 16,75 & 21,25 & 33,42 & 3,58 \\
\hline 17,07 & 19,93 & 17,26 & 19,74 & 33,48 & 3,52 \\
\hline 17,66 & 19,34 & 17,68 & 19,32 & 33,10 & 3,90 \\
\hline
\end{tabular}

Tabel VI. Hasil pengukuran emisi radiasi $30 \mathrm{MHz}-1 \mathrm{GHz}$ Speaker $\mathrm{SB}_{7}, \mathrm{SB}_{8}$ dan $\mathrm{SB}_{9}$

\begin{tabular}{|c|c|c|c|c|c|}
\hline \multicolumn{2}{|c|}{$\mathbf{S B}_{\mathbf{7}}$} & \multicolumn{2}{c|}{$\mathbf{S B}_{\mathbf{8}}$} & \multicolumn{2}{c|}{$\mathbf{S B}_{\mathbf{9}}$} \\
\hline $\boldsymbol{Q p}$ & Margin & $\boldsymbol{Q} \boldsymbol{p}$ & Margin & $\boldsymbol{Q p}$ & Margin \\
\hline$(\mathbf{d B} \boldsymbol{\mu V})$ & $\mathbf{( d B})$ & $\mathbf{( d B} \boldsymbol{\mu} \mathbf{V})$ & $\mathbf{( d B})$ & $(\mathbf{d B} \boldsymbol{\mu V})$ & $(\mathbf{d B})$ \\
\hline 19,76 & 10,34 & 19,82 & 10,18 & 19,65 & 10,35 \\
\hline 18,78 & 11,22 & 16,02 & 13,98 & 16,01 & 13,99 \\
\hline 15,27 & 14,73 & 12,06 & 17,94 & 15,46 & 14,54 \\
\hline 19,85 & 10,15 & 11,88 & 18,12 & 27,17 & 9,83 \\
\hline 22,45 & 7,65 & 18,43 & 18,57 & 27,90 & 9,10 \\
\hline
\end{tabular}

Pada hasil pengukuran nilai emisi radiasi speaker aktif dengan sumber daya baterai pada frekuensi 30 $\mathrm{MHz}$ - $1 \mathrm{GHz}$, didapatkan nilai quasipeak semua speaker berada di bawah nilai limit pada CISPR 32. Semua speaker dengan baterai lulus uji pada emisi radiasi $30 \mathrm{MHz}-1 \mathrm{GHz}$. Nilai margin quasipeak pada 7 speaker dengan baterai, memiliki nilai margin lebih dari $10 \mathrm{~dB}$, hanya ada 2 speaker ( $\mathbf{S B}_{3}$ dan $\mathbf{S B}_{6}$ ) yang memiliki nilai margin quasipeak dibawah $10 \mathrm{~dB}$. Nilai rata-rata margin antara quasipeak dan limit CISPR 32 terbesar terdapat pada speaker $\mathbf{S B} 4$ sebesar 18,23 dB dan nilai rata-rata margin terendah terdapat pada speaker SB6 yaitu 3,83 dB.

Tabel VII. Hasil pengukuran emisi radiasi $30 \mathrm{MHz}-1 \mathrm{GHz}$ Speaker $\mathrm{SB}_{1}, \mathrm{SB}_{2}$ dan $\mathrm{SB}_{3}$

\begin{tabular}{|c|c|c|c|c|c|}
\hline \multicolumn{2}{|c|}{$\mathbf{S N}_{\mathbf{1}}$} & \multicolumn{2}{c|}{$\mathbf{S N}_{\mathbf{2}}$} & \multicolumn{2}{c|}{$\mathbf{S N}_{\mathbf{3}}$} \\
\hline $\boldsymbol{Q p}$ & Margin & $\boldsymbol{Q p}$ & Margin & $\boldsymbol{Q p}$ & Margin \\
\hline $\mathbf{( d B} \boldsymbol{\mu} \mathbf{V})$ & $\mathbf{( d B})$ & $(\mathbf{d B} \boldsymbol{\mu} \mathbf{V})$ & $\mathbf{( d B})$ & $(\mathbf{d B} \boldsymbol{\mu V})$ & $(\mathbf{d B})$ \\
\hline 29,85 & 0,15 & 48,72 & $-18,72$ & 19,29 & 10,71 \\
\hline 25,86 & 4,14 & 54,71 & $-24,71$ & 16,27 & 13,73 \\
\hline 33,07 & $-3,07$ & 36,73 & $-6,73$ & 11,19 & 18,81 \\
\hline 24,37 & 5,63 & 34,68 & $-4,68$ & 11,92 & 18,08 \\
\hline 32,59 & $-2,59$ & 39,19 & $-9,19$ & 10,25 & 19,75 \\
\hline
\end{tabular}

Tabel VIII. Hasil pengukuran emisi radiasi $30 \mathrm{MHz}-1 \mathrm{GHz}$ Speaker $\mathrm{SB}_{4}, \mathrm{SB}_{5}$ dan $\mathrm{SB}_{6}$

\begin{tabular}{|c|c|c|c|c|c|}
\hline \multicolumn{2}{|c|}{$\mathbf{S N}_{\mathbf{4}}$} & \multicolumn{2}{c|}{$\mathbf{S N}_{\mathbf{5}}$} & \multicolumn{2}{c|}{$\mathbf{S N}_{\mathbf{6}}$} \\
\hline $\boldsymbol{Q p}$ & Margin & $\boldsymbol{Q p}$ & Margin & $\boldsymbol{Q p}$ & Margin \\
\hline $\mathbf{( \mathbf { B } \boldsymbol { \mu } \mathbf { V } )}$ & $\mathbf{( d B})$ & $(\mathbf{d B} \boldsymbol{\mu V})$ & $\mathbf{( d B})$ & $(\mathbf{d B} \boldsymbol{\mu V})$ & $(\mathbf{d B})$ \\
\hline 19,80 & 10,20 & 29,27 & 0,73 & 20,34 & 9,66 \\
\hline 19,90 & 10,10 & 30,85 & $-0,85$ & 22,16 & 7,84 \\
\hline 24,89 & 5,11 & 29,09 & 0,91 & 21,89 & 8,11 \\
\hline 28,37 & 1,63 & 29,67 & 0,33 & 20,91 & 9,09 \\
\hline 24,55 & 5,45 & 28,77 & 1,23 & 17,31 & 12,69 \\
\hline
\end{tabular}

Tabel IX. Hasil pengukuran emisi radiasi $30 \mathrm{MHz}-1 \mathrm{GHz}$ Speaker $\mathrm{SB}_{7}, \mathrm{SB}_{8}$ dan $\mathrm{SB}_{9}$

\begin{tabular}{|c|c|c|c|c|c|}
\hline \multicolumn{2}{|c|}{$\mathbf{S N}_{\mathbf{7}}$} & \multicolumn{2}{c|}{$\mathbf{S N}_{\mathbf{8}}$} & \multicolumn{2}{c|}{$\mathbf{S N}_{\mathbf{9}}$} \\
\hline $\boldsymbol{Q} \boldsymbol{p}$ & Margin & $\boldsymbol{Q p}$ & Margin & $\boldsymbol{Q p}$ & Margin \\
\hline$(\mathbf{d B} \boldsymbol{\mu} \mathbf{V})$ & $(\mathbf{d B})$ & $(\mathbf{d B} \boldsymbol{\mu V})$ & $(\mathbf{d B})$ & $(\mathbf{d B} \boldsymbol{\mu V})$ & $(\mathbf{d B})$ \\
\hline 32,90 & $-2,90$ & 19,71 & 10,29 & 26,47 & 3,53 \\
\hline 34,45 & $-4,45$ & 15,63 & 14,37 & 18,13 & 11,87 \\
\hline 29,90 & 0,10 & 26,56 & 3,44 & 27,01 & 2,99 \\
\hline 20,00 & 10,00 & 35,05 & $-5,05$ & 32,33 & $-2,33$ \\
\hline 36,32 & $-6,32$ & 20,69 & 9,31 & 29,82 & 0,18 \\
\hline
\end{tabular}

Pada hasil pengukuran nilai emisi radiasi speaker aktif dengan kabel suplai listrik langsung, terdapat 6 (enam) speaker aktif yang gagal dalam pengjian emisi radiasi $30 \mathrm{MHz}-1 \mathrm{GHz}$, hanya terapat 3 (tiga) speaker yang memenuhi persyaratan uji CISPR 32. Pada speaker $\mathbf{S N}_{2}$ semua nilai quasipeak melebihi nilai limit. Nilai rata-rata margin antara quasipeak dan limit CISPR 32 terbesar terdapat pada speaker $\mathbf{S N}_{3}$ sebesar $16,21 \mathrm{~dB}$ dan nilai rata-rata margin terendah terdapat pada speaker $\mathbf{S N}_{2}$ yaitu $-12,81 \mathrm{~dB}$.

\section{B. EMISI RADIASI FREKUENSI $1-6 \mathrm{GHz}$}

Hasil pengukuran nilai maksimum peak ( $\boldsymbol{M} \boldsymbol{p}$ ) pada frekuensi $1-6 \mathrm{GHz}$, speaker aktif dengan baterai (SB) diperlihatkan pada Tabel X, 11 dan 12. Sedangkan hasil pengukuran speaker aktif dengan kabel suplai langsung (SN) diperlihatkan pada Tabel XIII, 14 dan 15 .

Tabel X. Hasil pengukuran emisi radiasi $1-6 \mathrm{GHz}$ Speaker $\mathrm{SB}_{1}$,

\begin{tabular}{|c|c|c|c|c|c|}
\multicolumn{2}{|c|}{$\mathbf{S B}_{\mathbf{1}}$} & \multicolumn{2}{c|}{$\mathbf{S B}_{\mathbf{2}}$} & \multicolumn{2}{c|}{$\mathbf{S B}_{\mathbf{3}}$} \\
\hline $\boldsymbol{M} \boldsymbol{p}$ & Margin & $\boldsymbol{M} \boldsymbol{p}$ & Margin & $\boldsymbol{M} \boldsymbol{p}$ & Margin \\
\hline$(\mathbf{d B} \boldsymbol{\mu V})$ & $(\mathbf{d B})$ & $\mathbf{( d B} \boldsymbol{\mu} \mathbf{V})$ & $(\mathbf{d B})$ & $(\mathbf{d B} \boldsymbol{\mu V})$ & $(\mathbf{d B})$ \\
\hline 48,90 & 21,10 & 36,20 & 33,80 & 48,19 & 25,81 \\
\hline 48,18 & 21,82 & 50,21 & 23,79 & 48,46 & 25,54 \\
\hline
\end{tabular}

Tabel XI. Hasil pengukuran emisi radiasi $1-6 \mathrm{GHz}$ Speaker $\mathrm{SB}_{4}$, $\mathrm{SB}_{5}$ dan $\mathrm{SB}_{6}$

\begin{tabular}{|c|c|c|c|c|c|}
\hline \multicolumn{2}{|c|}{$\mathbf{S B}_{\mathbf{4}}$} & \multicolumn{2}{c|}{$\mathbf{S B}_{\mathbf{5}}$} & \multicolumn{2}{c|}{$\mathbf{S B}_{\mathbf{6}}$} \\
\hline $\boldsymbol{M} \boldsymbol{p}$ & Margin & $\boldsymbol{M} \boldsymbol{p}$ & Margin & $\boldsymbol{M} \boldsymbol{p}$ & Margin \\
\hline $\mathbf{( d B} \boldsymbol{\mu V})$ & $\mathbf{( d B})$ & $\mathbf{( d B} \boldsymbol{\mu V})$ & $\mathbf{( d B})$ & $(\mathbf{d B} \boldsymbol{\mu V})$ & $(\mathbf{d B})$ \\
\hline 41,34 & 28,66 & 52,59 & 17,41 & 48,76 & 25,24 \\
\hline 48,56 & 25,44 & 47,33 & 22,67 & 48,32 & 25,68 \\
\hline
\end{tabular}

Tabel XII. Hasil pengukuran emisi radiasi $1-6 \mathrm{GHz}$ Speaker $\mathrm{SB}_{7}$, $\mathrm{SB}_{8}$ dan $\mathrm{SB}_{9}$

\begin{tabular}{|c|c|c|c|c|c|}
\hline \multicolumn{2}{|c|}{$\mathbf{S B}_{7}$} & \multicolumn{2}{c|}{$\mathbf{S B}_{\mathbf{8}}$} & \multicolumn{2}{c|}{$\mathbf{S B}_{\mathbf{9}}$} \\
\hline $\boldsymbol{M} \boldsymbol{p}$ & Margin & $\boldsymbol{M} \boldsymbol{p}$ & Margin & $\boldsymbol{M} \boldsymbol{p}$ & Margin \\
\hline $\mathbf{( d B} \boldsymbol{\mu} \mathbf{V})$ & $\mathbf{( d B})$ & $(\mathbf{d B} \boldsymbol{\mu} \mathbf{V})$ & $(\mathbf{d B})$ & $(\mathbf{d B} \boldsymbol{\mu} \mathbf{V})$ & $(\mathbf{d B})$ \\
\hline 48,42 & 25,58 & 48,29 & 25,71 & 48,68 & 25,32 \\
\hline 49,23 & 24,77 & 48,08 & 25,92 & 49,55 & 24,45 \\
\hline
\end{tabular}

Tabel XIII. Hasil pengukuran emisi radiasi $1-6 \mathrm{GHz}$ Speaker $\mathrm{SB}_{1}$, $\mathrm{SB}_{2}$ dan $\mathrm{SB}_{3}$

\begin{tabular}{|c|c|c|c|c|c|}
\hline \multicolumn{2}{|c|}{$\mathbf{S N}_{\mathbf{1}}$} & \multicolumn{2}{c|}{$\mathbf{S N}_{\mathbf{2}}$} & \multicolumn{2}{c|}{$\mathbf{S N}_{\mathbf{3}}$} \\
\hline $\boldsymbol{M} \boldsymbol{p}$ & Margin & $\boldsymbol{M} \boldsymbol{p}$ & Margin & $\boldsymbol{M p}$ & Margin \\
\hline$(\mathbf{d B} \boldsymbol{\mu V})$ & $(\mathbf{d B})$ & $(\mathbf{d B} \boldsymbol{\mu V})$ & $(\mathbf{d B})$ & $(\mathbf{d B} \boldsymbol{\mu V})$ & $(\mathbf{d B})$ \\
\hline 44,02 & 25,98 & 60,25 & 9,75 & 56,45 & 13,55 \\
\hline 33,68 & 36,32 & 43,26 & 26,74 & 35,86 & 34,14 \\
\hline
\end{tabular}

Tabel XIV. Hasil pengukuran emisi radiasi $1-6 \mathrm{GHz}$ Speaker $\mathrm{SB}_{4}, \mathrm{SB}_{5}$ dan $\mathrm{SB}_{6}$

\begin{tabular}{|c|c|c|c|c|c|}
\hline \multicolumn{2}{|c|}{$\mathbf{S N}_{\mathbf{4}}$} & \multicolumn{2}{c|}{$\mathbf{S N}_{\mathbf{5}}$} & \multicolumn{2}{c|}{$\mathbf{S N}_{\mathbf{6}}$} \\
\hline $\boldsymbol{M} \boldsymbol{p}$ & Margin & $\boldsymbol{M} \boldsymbol{p}$ & Margin & $\boldsymbol{M p}$ & Margin \\
\hline$(\mathbf{d B} \boldsymbol{\mu V})$ & $\mathbf{( d B})$ & $(\mathbf{d B} \boldsymbol{\mu V})$ & $(\mathbf{d B})$ & $(\mathbf{d B} \boldsymbol{\mu V})$ & $(\mathbf{d B})$ \\
\hline 33,37 & 36,63 & 44,30 & 25,70 & 47,74 & 26,26 \\
\hline 39,18 & 30,82 & 64,20 & 5,80 & 48,63 & 25,37 \\
\hline
\end{tabular}

Tabel XV. Hasil pengukuran emisi radiasi $1-6 \mathrm{GHz}$ Speaker $\mathrm{SB}_{7}$, $\mathrm{SB}_{8}$ dan $\mathrm{SB}_{9}$

\begin{tabular}{|c|c|c|c|c|c|}
\hline \multicolumn{2}{|c|}{$\mathbf{S N}_{7}$} & \multicolumn{2}{c|}{ SN8 } & \multicolumn{2}{c|}{ SN9 } \\
\hline $\boldsymbol{M} \boldsymbol{p}$ & Margin & $\boldsymbol{M} \boldsymbol{p}$ & Margin & $\boldsymbol{M} \boldsymbol{p}$ & Margin \\
\hline$(\mathbf{d B} \boldsymbol{\mu V})$ & $\mathbf{( d B})$ & $\mathbf{( d B} \boldsymbol{\mu V})$ & $(\mathbf{d B})$ & $(\mathbf{d B} \boldsymbol{\mu V})$ & $(\mathbf{d B})$ \\
\hline 44,23 & 25,77 & 49,13 & 24,87 & 34,62 & 35,38 \\
\hline 38,61 & 31,39 & 48,81 & 25,19 & 48,00 & 26,00 \\
\hline
\end{tabular}


Pada hasil pengukuran nilai emisi radiasi speaker aktif pada frekuensi $1-6 \mathrm{GHz}$, didapatkan nilai Max.Peak semua speaker berada di bawah nilai limit pada CISPR 32. Semua speaker aktif memenuhi persyaratan uji CISPR 32.

Hasil pengujian speaker aktif dengan baterai dan speaker aktif dengan sumber listrik PLN menunjukan bahwa speaker aktif dengan baterai memiliki nilai emisi radiasi yang jauh lebih baik jika dibandingkan dengan speaker aktif listrik PLN padafrekuensi 30 $\mathrm{MHz}-1 \mathrm{GHz}$. Hal ini dapat disebabkan karena kabel power suplai pada speaker aktif dapat berubah menjadi antenna ketika dialiri arus listrik. Selain itu pada jalajala listrik PLN juga terdapat noise selama pendistribusian listrik oleh PLN ke konsumen. Penggunaan adaptor DC juga tidak disarankan karena dapat menghasilkan emsisi radiasi yang tinggi seperti yang terdapat pada speaker aktif $\mathbf{S N}_{\mathbf{2}}$.

Penggunaan baterai sebagai sumber tegangan pada speaker aktif dapat mengurangi nilai emisi radiasi yang dihasilkan, karena tidak memerlukan kabel suplai daya listrik saat dilakukan pengujian. Selain itu untuk rangkaian power supply di dalam perangkat juga tidak memberikan dampak emisi radiasi yang besar jika disbandingkan dengan menggunakan suplai jala-jala listrik. Penggunaan baterai juga memberikan manfaat lain jika dibandingkan dengan sumber tegangan jalajala listrik, yaitu speaker menjadi lebih fleksibel dalam penggunaan nya karena dapat dibawa dan digunakan kapan saja ketika baterai terisi. Baterai memiliki spesifikasi, kelebihan, dan kekurangan yang berbeda. Ada banyak pertimbangan untuk memilih baterai untuk kendaraan listrik termasuk biaya awal, waktu hidup, massa, volume, sensitivitas suhu, akses ke perawatan dan akses ke produk ${ }^{17}$.

\section{KESIMPULAN}

Hasil pengukuran speaker aktif di ruang semi anechoic chamber pada frekuensi $30 \mathrm{MHz}-1 \mathrm{GHz}$, menunjukkan speaker aktif dengan menggunakan baterai memiliki nilai emisi radiasi elektromagnetik yang lebih rendah jika dibandingkan speaker aktif dengan kabel suplai listrik langsung ${ }^{13}$. Semua speaker aktif dengan baterai lulus persyaratan uji CISPR 32 emisi radiasi elektromagnetik pada frekuensi $30 \mathrm{MHz}$ - $1 \mathrm{GHz}$. Terdapat 6 (enam) speaker aktif dengan suplai daya langsung yang gagal memenuhi persyaratan uji CISPR 32 dan hanya terapat 3 (tiga) speaker yang memenuhi persyaratan uji. Kabel suplai listrik pada speaker aktif dapat berubah menjadi antena ketika dialiri arus listrik, sehingga dapat menghasilkan emisi radiasi yang tinggi. Semua speaker aktif memenuhi persyaratan uji CISPR 32 pada frekuensi 1 - $6 \mathrm{GHz}$ pada jarak pengukuran 3 meter. Perlu adanya penelitian lebih lanjut mengenai pengaruh pemilihan jenis baterai dan versi modul bluetooth yang digunakan terhadap emisi radiasi elektromagnetik.

\section{UCAPAN TERIMA KASIH}

Ucapan terima kasih diucapkan kepada Baristand Industri khususnya Laboratorium Elektronika dan Telematika yang menyediakan seluruh fasilitas pengujian EMC, khususnya untuk pengukuran nilai emisi radiasi elektromagnetik pada penelitian ini.

\section{DAFTAR PUSTAKA}

1. Bisdikian, C. An overview of the Bluetooth wireless technology. IEEE Commun. Mag. (2001). doi:10.1109/35.968817

2. Sairam, K. V. S. S. S. S., Gunasekaran, N. \& Rama Reddy, $\mathrm{S}$. Bluetooth in wireless communication. IEEE Commun. Mag. (2002). doi:10.1109/MCOM.2002.1007414

3. Lodha, R., Gupta, S., Jain, H. \& Narula, H. Bluetooth Smart based attendance management system. in Procedia Computer Science

(2015). doi:10.1016/j.procs.2015.03.094

4. Gratton, D. A. \& Gratton, D. A. Bluetooth low energy. in The Handbook of Personal Area Networking Technologies and Protocols (2013). doi:10.1017/cbo9780511979132.013

5. Gomez, C., Oller, J. \& Paradells, J. Overview and evaluation of bluetooth low energy: An emerging lowpower wireless technology. Sensors (Switzerland) (2012). doi:10.3390/s120911734

6. Ferro, E. \& Potortì, F. Bluetooth and Wi-Fi wireless protocols: A survey and a comparison. IEEE Wireless Communications

(2005). doi:10.1109/MWC.2005.1404569

7. Park, H. H., Park, H. \& Lee, H. S. A Simple Method of Estimating the Radiated Emission From a Cable Attached to a Mobile Device. IEEE Trans. Electromagn. Compat. 55, 257-264 (2013).

8. Balmori, A. Electromagnetic pollution from phone masts. Effects on wildlife. Pathophysiology 16, 191-199 (2009).

9. Galeev, A. The effects of microwave radiation from mobile telephones on humans and animals. Neurosci. Behav. Physiol. 30, 187-94 (2000).

10. Nicolae, P. M. Stoica, C. M. \& Mihai, G. Conducted emission measurements for a laptop. 2014 Int. Conf. Appl. Theor. Electr. ICATE 2014 - Proc. 2-5 (2014). doi:10.1109/ICATE.2014.6972659

11. Armstrong, K. Guide to Testing Conducted Emissions (Based on the Methods in EN 55022 and EN 55011). In Compliance 14-27 (2011).

12. Lapinsky, S. E. \& Easty, A. C. Electromagnetic interference in critical care. J. Crit. Care 21, 267-270 (2006).

13. Song, E., Park, H. B. \& Park, H. H. An evaluation method for radiated emissions of components and modules in mobile devices. IEEE Trans. Electromagn. Compat. 56, 1020-1026 (2014).

14. Braun, S. A novel time-domain EMI measurement system for measurement and evaluation of discontinuous disturbance according to CISPR 14 and CISPR 16. IEEE Int. Symp. Electromagn. Compat. 480-483 (2011). doi:10.1109/ISEMC.2011.6038359

15. Song, E., Park, H. B. \& Park, H. H. An electromagnetic interference (EMI) evaluation method for components in mobile devices. IEEE Int. Symp. Electromagn. Compat. 783-786 (2013). doi:10.1109/ISEMC.2013.6670516

16. Arnett, D. CISPR 32 vs. ANSI C63.4: Color bars, scrolling $\mathrm{H}$ patterns, and the quasi-peak detector. in IEEE International Symposium on Electromagnetic Compatibility (2012). doi:10.1109/ISEMC.2012.6351835

17. Thowil Afif, M. \& Ayu Putri Pratiwi, I. Analisis Perbandingan Baterai Lithium-Ion, Lithium-Polymer, Lead Acid dan Nickel-Metal Hydride pada Penggunaan Mobil Listrik - Review. J. Rekayasa Mesin (2015). doi:10.21776/ub.jrm.2015.006.02.1 